\title{
ANALISIS PENERAPAN BALANCED SCORECARD UNTUK MENGUKUR KINERJA PERUSAHAAN PADA PT. XYZ TBK.
}

\author{
Sudiman \\ Program Studi Magister Manajemen Universitas Tarumanagara \\ sudiman.wang@gmail.com
}

\begin{abstract}
The Balanced Scorecard has been shown to be a valuable tool for management control in organization, particulary in the current context where continuous improvement of results and level of quality is demanded in both the private and public spheres. The Balanced Scorecard is a measurement and management system that views a business unit's performance from four perspectives includes financial, customer, internal business process, and learning and growth.

This research was analyzed using Balanced Scorecard Analysis, Liquidity Ratio Analysis, PEST Analysis and SWOT Analysis. The Analysis to explore more detail about the measurement of business performance from four perspectives includes financial, customer, internal business process, and learning and growth at PT. XYZ Tbk. This research concludes that Balanced Scorecard measurement gives the company more detail about its business performance, and enable the company to create strategies which linked in Balanced Scorecard perspectives in term to increase stakeholders value.
\end{abstract}

Keywords: Business Strategy, Business Performance, Liquidity Ratio analysis, PEST analysis, SWOT analysis, Balanced Scorecard analysis

\section{PENDAHULUAN}

Semakin pesatnya persaingan bisnis secara global dalam beberapa tahun belakangan ini menyebabkan banyak perusahaan mulai melakukan pembenahan terhadap bebagai strategi yang digunakan dalam rangka memenangkan kompetisi. Agar dapat bersaing, maka perusahaan harus mampu untuk membuat strategi yang dapat diukur kinerjanya. Pengukuran kinerja perusahaan sebaiknya harus didasarkan pada tujuan strategis perusahaan yang berdasarkan pada kebutuhan pasar, hal ini dapat dilakukan dengan melakukan evaluasi terhadap faktor-faktor internal perusahaan maupun faktor-faktor eksternal perusahaan. Sistem pengukuran kinerja selama ini umumnya dilakukan secara konvensional hanya berdasarkan laporan keuangan saja seperti laporan Neraca maupun Laporan Laba-Rugi. Aspek non keuangan harus mendapat perhatian yang cukup serius karena pada dasarnya peningkatan kinerja keuangan tidak terlepas dari aspek non-keuangan yaitu peningkatan efektifitas biaya, peningkatan komitmen organisasi dalam melakukan pembenahan secara internal prosesnya dan bahkan peningkatan kepercayaan pelanggan terhadap produk yang dihasilkan sangat diperlukan. Faktor non keuangan lainnya seperti faktor politik, ekonomi, sosial dan bahkan perkembangan teknologi juga memberikan peranan yang cukup besar terhadap peningkatan kinerja suatu perusahaan. Balanced Scorecard (BSC) merupakan salah satu metode pengukuran kinerja perusahaan secara keseluruhan yang dapat mengukur kinerja perusahaan dari aspek keuangan dan non-keuangan. Balanced Scorecard (BSC) mengukur kinerja berdasarkan empat perspektif, yaitu perspektif keuangan, perspektif pelanggan, perspektif proses bisnis internal dan perspektif pertumbuhan dan pembelajaran. Keempat perspektif tersebut menjadi indikator pengukuran kinerja yang saling melengkapi. 
PT. XYZ Tbk. adalah salah satu pengembang property terdepan di Indonesia dengan fokus dibidang pengembangan property kelas menengah atas. Perusahaan saat ini melakukan pengukuran kinerja bisnis yang difokuskan berdasarkan aspek keuangan dengan melihat laporan keuangan seperti Neraca dan Laporan Laba-Rugi. Pengukuran kinerja bisnis berdasarkan aspek keuangan tersebut dirasa perusahaan cukup sulit untuk mengukur kinerja perusahaan secara keseluruhan, sehingga hal ini dapat menghambat perusahaan untuk mencapai pertumbuhan bisnisnya secara optimal. Peneliti membatasi penelitian ini dengan memfokuskan penelitian pada pengukuran kinerja perusahaan PT. XYZ Tbk. dengan menggunakan metode Balanced Scorecard. Rumusan masalah pada penelitian ini adalah 1) bagaimana perusahaan dapat melakukan pengukuran kinerja bisnis yang dijalankan ditinjau dari empat perspektif dalam Balanced Scorecard? dan 2) bagaimana cara perusahaan membuat berbagai langkah strategis yang dibutuhkan dalam rangka meningkatkan kinerja perusahaan?

\section{TINJAUAN PUSTAKA}

Balanced Scorecard merupakan suatu alat ukur yang memberikan manajer suatu sudut pandang bisnis yang cepat dan komprehensif, termasuk ukuran keuangan yang memberitahukan hasil yang telah dilakukan, melengkapi ukuran keuangan dengan ukuran operasional pada kepuasan pelanggan, proses internal, dan aktifitas inovasi dan perbaikan organisasi - ukuran operasional yang menjadi penggerak kinerja keuangan di masa yang akan datang (Kaplan dan Norton, 1996). Perusahaan menggunakan pengukuran Balanced Scorecard sebagai sebuah sistem manajemen strategis untuk menghasilkan berbagai proses manajemen penting dan mengelola strategi jangka panjang. Aspek-aspek yang diukur dalam Balanced Scorecard terdiri dari empat perspektif yaitu antara lain perspektif keuangan, perspektif pelanggan, perspektif proses bisnis internal, perspektif pembelajaran dan pertumbuhan. Integrasi empat perspektif tercermin dalam Kerangka Kerja Balanced Scorecard.

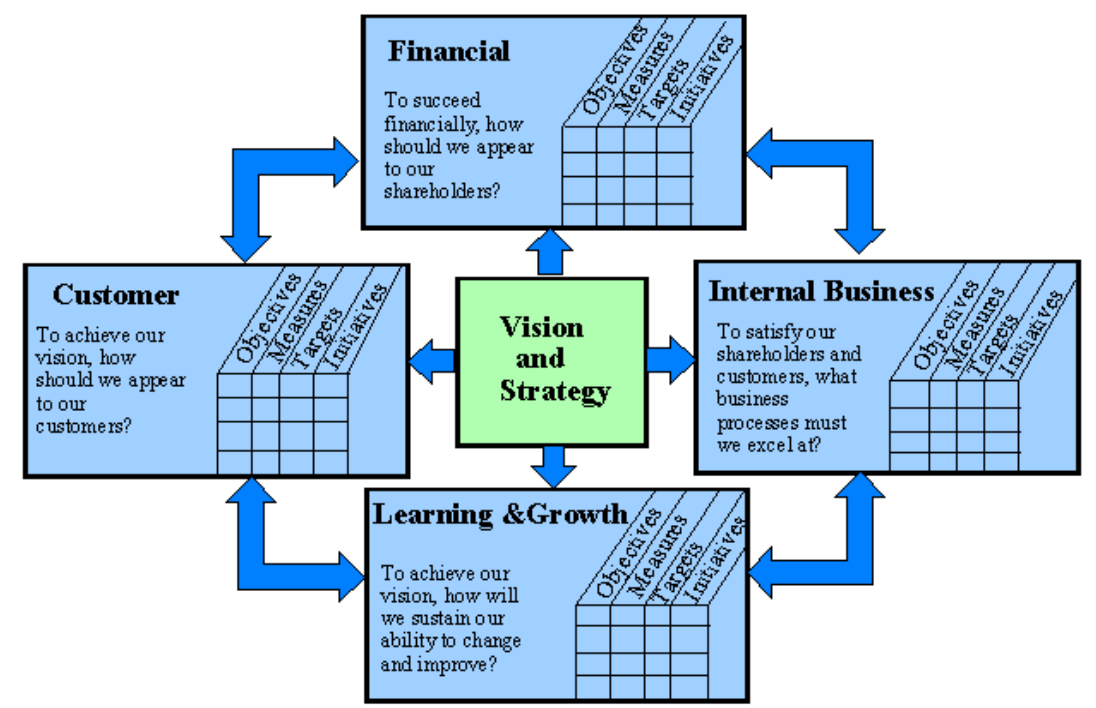

Gambar 1 Kerangka Kerja Balanced Scorecard

\section{METODE PENELITIAN}

Metode penelitian yang digunakan dalam pembuatan penelitian ini menggunakan metode penelitian secara kualitatif, dimana penelitian ini akan bersifat deskriptif dan cenderung menggunakan analisis yang didasarkan pada landasan teori. Penelitian ini dilakukan dengan cara mengumpulkan semua informasi yang bersifat aktual terhadap objek yang diteliti seeara langsung dengan menggunakan metode observasi dan wawaneara maupun 
menggunakan kuesioner yang ditujukan pada manajemen PT. XYZ Tbk. Lokasi dari objek penelitian tersebut berada di kota Jakarta Pusat. Periode data yang digunakan pada penelitian ini tahun 2014 s/d tahun 2016. Data tersebut akan digunakan pada tahapan analisis dan pembahasan.

\section{HASIL DAN PEMBAHASAN}

\section{Identifikasi Kinerja Bisnis Perusahaan}

Proses identifikasi kinerja bisnis perusahaan dilakukan dalam rangka untuk mengumpulkan faktor-faktor yang dapat menyebabkan pertumbuhan ataupun penurunan suatu kinerja perusahaan. Faktor-faktor yang didapat selanjutnya dilakukan analisis untuk melihat kinerja bisnis suatu perusahaan. Dengan adanya analisis tersebut, maka perusahaan dapat menentukan strategi yang tepat untuk digunakan dalam proses pengambilan keputusan bisnis perusahaan..

\section{Analisis PEST (Political, Economic, Social, Technology)}

Analisis lingkungan eksternal merupakan gabungan dari beberapa faktor yang mempengaruhi pertumbuhan suatu jenis industri diluar dari faktor internal perusahaan yaitu berupa faktor PEST antara lain: Politik, Ekonomi, Sosial, dan Teknologi. Berikut adalah penjelasan dari analisis PEST.

\section{Politik}

- $\quad(+)$ Kondisi politik dalam negeri relatif stabil

- (+) Paket kebijakan di sektor property sebagai stimulusi untuk melakukan investasi sebut saja program Tax Amnesty

- (+) Tingkat suku bunga relatif menurun

- $\quad(-)$ Kenaikan Upah Minimum Provinsi setiap tahun

\section{Sosial}

- (+) Perubahan gaya hidup dari masyarakat perkotaan dalam hal hunian yang menginginkan produk property sesuai dengan ekspektasi

- (+) Proyeksi pertumbuhan penduduk indonesia yang cenderung mengalami peningkatan setiap tahunnya

\section{Ekonomi}

- (+) Tingkat pertumbuhan ekonomi Indonesia yang relatif stabil dan positif diangka $4.5 \%$ s/d $5 \%$ an

- (+) Tingkat inflasi yang relatif stabil

\section{Teknologi}

- (+) Perkembangan teknologi yang begitu pesat dalam beberapa tahun terakhir

- (+) Berkembangnya alternatif baru dalam hal pemasaran produk melalui Digital Marketing

- (+) Tingginya pengguna Smartphone dan Internet di Indonesia

Gambar 2 Analisis PEST

\section{Analisis SWOT (Strengths, Weakness, Opportunities, Threats)}

Kondisi perusahaan dapat ditentukan oleh kombinasi faktor internal dan eksternal. Analisis SWOT mengidentifikasi berbagai faktor internal (Strengths, Weaknesses) dan faktor eksternal (Opportunities, Threats). Tujuan analisis ini untuk melihat kekuatan (Strengths) dan peluang (Opportunities) sekaligus mengatasi kelemahan (Weaknesses) dan ancaman (Threats). Berikut ini SWOT PT. XYZ Tbk 


\begin{tabular}{|c|c|c|}
\hline & $\begin{array}{l}\text { STRENGTHS } \\
\text { 1. Struktur keuangan yang cukup, karena ditopang oleh } \\
\text { keuangan perusahaan induk } \\
\text { 2. Poduk dan Harga yang kompetitif } \\
\text { 3. Aset berupa landbank yang memiliki lokasi yang } \\
\text { sangat strategis } \\
\text { 4. Sistem Informasi Manajemen yang terintegrasi } \\
\text { 5. Pengalaman yang cukup lama dalam dunia property. }\end{array}$ & $\begin{array}{l}\text { WEAKNESS } \\
\text { 1. Prioritas dalam hal pengembangan dan kompetensi } \\
\text { karyawan yang relatif kecil } \\
\text { 2. Layanan purna jual yang belum optimal } \\
\text { 3. Strategi pemasaran yang belum optimal } \\
\text { 4. Proses pembangunan yang tidak selalu tepat waktu } \\
\text { 5. Belum mampu melakukan pengelolaan Budaya Oganisasi } \\
\text { secara optimal. } \\
\text { 6. Kebijakan dan Prosedur Operasional yang belum berjalan } \\
\text { optimal. }\end{array}$ \\
\hline $\begin{array}{l}\text { OPPORTUNITIES } \\
\text { 1. Populasi masyarakat yang cukup besar } \\
\text { 2. Tingkat suku bunga KPR yang relatif } \\
\text { menurun } \\
\text { 3. Perkembangan teknologi yang mengalami } \\
\text { peningkatan yang cukup signifikan } \\
\text { 4. Pemerintah masih memperhatikan kondisi } \\
\text { property dengan memberikan stimulus yang } \\
\text { dapat mendongkrak pasar property. } \\
\text { 5. Banyaknya agen pemasaran yang memiliki } \\
\text { kemampuan untuk menjual produk }\end{array}$ & $\begin{array}{l}\text { Strategi SO } \\
\text { 1. Meningkatkan pendapatan dengan cara melakukan } \\
\text { penetrasi pasar dengan mengadakan event-event atau } \\
\text { promosi-promosi, seperti pemberian Gimmick (S1, S2, } \\
\text { S3, O1, O2, O4) } \\
\text { 2. Meningkatkan efektivitas pemasaran dengan } \\
\text { melaksanakan strategi pemasaran sesuai dengan } \\
\text { perkembangan teknologi dengan masuk kedalam } \\
\text { pemasaran produk melalui media Online (S1, S2, O3, } \\
\text { O4) } \\
\text { 3. Meningkatkan kepuasan pelanggan dengan cara } \\
\text { melakukan pengembangan suatu konsep hunian baru } \\
\text { berdasarkan trend saat ini yang dapat diminati oleh } \\
\text { para konsumen (S1, S3, S5, O3) } \\
\text { 4. Meningkatkan jumlah pelanggan baru dengan cara } \\
\text { melakukan kerjasama dengan para member dan Agent } \\
\text { Property (S1, S2, S3, O5) } \\
\text { 5. Menciptakan persepsi pelanggan yang positif terhadap } \\
\text { produk yang ditawarkan }\end{array}$ & $\begin{array}{l}\text { Strategi WO } \\
\text { 1. Meningkatkan kepuasan pelanggan melalui peningkatan } \\
\text { layanan pelanggan dengan menjalankan konsep CRM (W2, } \\
\text { O3) } \\
\text { 2. Meningkatkan kinerja dan kompetensi karyawan dengan } \\
\text { melakukan training internal ataupun eksternal yang } \\
\text { berbasis teknologi (W1, O3) } \\
\text { 3. Meningkatkan efektivitas pemasaran melalui pelaksanaan } \\
\text { strategi pemasaran dengan masuk kedalam pemasaran } \\
\text { produk melalui Media Online (W3, O1, O2, O3, O4) } \\
\text { 4. Meningkatkan budaya organisasi perusahaan dengan cara } \\
\text { melakukan sosialisasi ke karyawan mengenai Visi, Misi } \\
\text { dan Values perusahaan. (W5, O3) } \\
\text { 5. Merencanakan dan melaksanakan proses pembanguan yang } \\
\text { tepat waktu (O1, O4, W4) } \\
\text { 6. Meningkatkan tata kelola perusahaan yang baik dengan } \\
\text { cara melaksanakan sosialisasi dan compliance audit ke } \\
\text { karyawan mengenai kebijakan dan prosedur operasional } \\
\text { (W6, O3) }\end{array}$ \\
\hline $\begin{array}{l}\text { THREATS } \\
\text { 1. Tingkat pertumbuhan ekonomi yang relatif } \\
\text { belum mengalami peningkatan yang } \\
\text { signifikan } \\
\text { 2. Turunnya daya beli masyarakat } \\
\text { 3. Nilai tukar mata uang asing yang cukup } \\
\text { fluktuatif } \\
\text { 4. Jumlah pesaing di industri property yang } \\
\text { semakin meningkat meningkatnya Upah } \\
\text { 5. Kecenderungan man } \\
\text { Minimum setiap tahunnya }\end{array}$ & $\begin{array}{l}\text { Strategi ST } \\
\text { 1. Meningkatkan efisiensi biaya tanpa mengurangi } \\
\text { kualitas produk dalam menjalankan operasional } \\
\text { perusahaan, seperti pemberlakukan strategi Supply By } \\
\text { Owner dalam pelaksanaan pembangunan proyek (S1, } \\
\mathrm{S} 4, \mathrm{~T} 2, \mathrm{~T} 3, \mathrm{~T} 5) \\
\text { 2. } \\
\text { Menjalankan strategi product development dengan } \\
\text { mengembangkan suatu produk yang diminati oleh } \\
\text { konsumen (S3, S5, T1, T2, T4) }\end{array}$ & $\begin{array}{l}\text { Strategi WT } \\
\text { 1. Meningkatkan kinerja dan kompetensi karyawan dengan } \\
\text { melakukan training internal ataupun eksternal (W1, T4, } \\
\text { T5) } \\
\text { 2. Meningkatkan efisiensi dan efektifitas kerja dengan } \\
\text { melakukan pembenahan kebijakan dan prosedur } \\
\text { operasional pada Budaya Organisasi (W5, W6, T4, T5) } \\
\text { 3. Meningkatkan kepuasan pelanggan melalui peningkatan } \\
\text { layanan pelanggan dengan menjalankan konsep CRM } \\
\text { (W2, W2, W4) }\end{array}$ \\
\hline
\end{tabular}

\section{Tabel 1 Matrix SWOT}

Berdasarkan hasil analisis SWOT diatas, maka terdapat 12 alternatif strategi yang dapat digunakan oleh PT. XYZ Tbk. untuk mengatasi para pesaingnya. Hasil analisis SWOT tersebut selanjutnya dapat digunakan oleh perusahaan dalam membuat dan menganalisis Balanced Scorecard.

\section{Analisis Balanced Scorecard Perspektif Keuangan}

Secara perspektif keuangan perusahaan melihat kinerja bisnis dengan cara memantau laporan keuangan tahunan dengan menggunakan tools seperti rasio likuiditas. Berdasarkan analisis rasio likuiditas dengan menggunakan data laporan keuangan tahun 2014, 2015 dan 2016 pada PT. XYZ Tbk., maka didapatkan hasil analisis sebagai berikut:

\begin{tabular}{|l|r|r|r|r|r|c|}
\hline \multicolumn{1}{|c|}{ Rasio } & Tahun 2014 & Tahun 2015 & Tahun 2016 & $\begin{array}{c}\text { \% } \\
\mathbf{2 0 1 4}- \\
\mathbf{2 0 1 5}\end{array}$ & $\begin{array}{c}\text { \% } \\
\mathbf{2 0 1 5}-\end{array}$ & $\begin{array}{c}\text { \% Rata-Rata } \\
\text { Kenaikan / } \\
\text { Penurunan }\end{array}$ \\
\hline Aset Lancar & $477,700,859,011$ & $583,413,951,262$ & $590,606,427,695$ & $22.13 \%$ & $1.23 \%$ & $11.68 \%$ \\
\hline Kewajiban Jangka Pendek & $490,566,324,200$ & $575,730,150,412$ & $373,448,368,017$ & $17.36 \%$ & $-35.13 \%$ & $-8.89 \%$ \\
\hline Rasio Lancar (Current Ratio) & $\mathbf{0 . 9 7}$ & $\mathbf{1 . 0 1}$ & $\mathbf{1 . 5 8}$ & $\mathbf{4 . 0 6} \%$ & $\mathbf{5 6 . 0 7 \%}$ & $\mathbf{3 0 . 0 7 \%}$ \\
\hline
\end{tabular}

Sumber: Data yang diolah dari Laporan Keuangan PT. XYZ Tbk. Tahun 2014 s/d 2016.

\section{Tabel 2 Rasio Lancar (Current Ratio)}

Berdasarkan tabel diatas, maka dapat dilihat bahwa terjadi kenaikan sebesar $4.06 \%$ atas rasio lancar dari yang sebelumnya 0.97 pada tahun 2014 menjadi 1.01 pada tahun 2015 . Hal 
ini disebabkan karena perusahaan mampu untuk meningkatkan aset lancarnya sebesar $22.13 \%$ pada tahun 2014 - 2015guna untuk menutupi kewajiban jangka pendeknya yang juga

mengalami kenaikan sebesar $17.36 \%$ pada tahun2014-2015. Terjadinya kenaikan tersebut juga menunjukkan adanya peningkatan kinerja keuangan dalam pengelolaan aset lancar dan kewajiban jangka pendeknya.

\begin{tabular}{|l|r|r|r|r|c|c|}
\hline \multicolumn{1}{|c|}{ Rasio } & Tahun 2014 & Tahun 2015 & Tahun 2016 & $\begin{array}{c}\text { \% } \\
\mathbf{2 0 1 4 -} \\
\mathbf{2 0 1 5}\end{array}$ & $\begin{array}{c}\text { \% } \\
\mathbf{2 0 1 5}-\begin{array}{c}\text { 2016 Rata-Rata } \\
\text { Kenaikan / } \\
\text { Penurunan }\end{array}\end{array}$ & $\begin{array}{c}\text { 2015 } \\
\text { Aset Lancar }\end{array}$ \\
\hline Kewajiban Jangka Pendek & $477,700,859,011$ & $583,413,951,262$ & $590,606,427,695$ & $22.13 \%$ & $1.23 \%$ & $11.68 \%$ \\
\hline Inventory & $490,566,324,200$ & $575,730,150,412$ & $373,448,368,017$ & $17.36 \%$ & $-35.13 \%$ & $-8.89 \%$ \\
\hline Rasio Cepat (Quick Ratio) & $28,662,861,410$ & $468,108,771,288$ & $637,824,217,055$ & $1533.15 \%$ & $36.26 \%$ & $784.70 \%$ \\
\hline
\end{tabular}

Sumber: Data yang diolah dari Laporan Keuangan PT. XYZ Tbk. Tahun 2014 s/d 2016.

Tabel 3 Rasio Cepat (Quick Ratio)

Selanjutnya tabel 3 menjelaskan rasio likuiditas yaitu rasio cepat (quick ratio) dimana terdapat penurunan quick ratio dari tahun 2014 - 2016 yaitu dari 0.92 menuju 0.20 dan terakhir minus 0.13. Penurunan ini dikarenakan terjadi penumpukan Inventory dimana terjadi peningkatan yang begitu signifikan nilai Inventory dari tahun 2014 - 2016 yaitu sebesar 1533.15\% pada tahun 2014 - 2015 dan 36.26\% pada tahun 2015 - 2016. Penumpukan Inventory dikarenakan banyak unit-unit hunian yang belum dapat dipasarkan karena kondisi daya beli yang relatif menurun pada tahun tersebut.

\section{Perspektif Pelanggan}

Secara perspektif pelanggan PT. XYZ Tbk. melihat bahwa salah satu indikator untuk melihat keberhasilan dari suatu strategi yang akan dijalankan oleh pelanggan adalah melihat feedback dari para pelanggannya terhadap produk dan layanan yang ditawarkan oleh perusahaan.

1. Tingkat Kepuasan Pelanggan: Dilihat dari sisi perspektif pelanggan maka tingkat kepuasan pelanggan pada PT. XYZ Tbk. kurang begitu baik, hal ini dikarenakan banyaknya komplain mengenai keterlambatan pembangunan.

2. Jumlah Pelanggan Baru: Perusahaan harus melakukan berbagai macam strategi untuk mendapatkan jumlah pelanggan baru. Strategi yang dipakai dapat dinyatakan berhasil dapat dilakukan dengan melihat pertumbuhan jumlah pelanggan baru yang membeli produk dari PT.XYZ Tbk.

3. Persepsi Pelanggan yang Positif Terhadap Produk yang Ditawarkan: Jika dilihat dari persepsi pelanggan yang positif terhadap produk yang ditawarkan, PT. XYZ Tbk. saat ini menawarkan produk-produk yang dibutuhkan oleh para pelanggan.

\section{Perspektif Proses Bisnis Internal}

Dilihat dari perspektif proses bisnis internal, saat ini PT. XYZ Tbk. dalam mencapai pendapatan maupun efisiensi biaya yang baik, maka diperlukan suatu proses yang baik juga. Proses bisnis internal yang dimaksud meliputi:

1. Peningkatan efektifitas pemasaran: Dalam pelaksanaannya PT. XYZ Tbk. telah menyiapkan beberapa strategi untuk peningkatan efektifitas pemasaran melalui pelaksanaan promosi Above the Line (ATL) dan Below the Line (BTL) baik offline maupun melalui media online. 
2. Perencanaan dan pelaksanaan pembangunan yang tepat waktu: PT. XYZ Tbk. saat ini menyiapkan beberapa proses yang baik yang dapat mendukung pelaksanaan tepat waktu, seperti:

- Membuat perencanaan dengan membuat timeline beserta tools monitoringnya.

- Pelaksanaan serah terima yang lebih tepat waktu melalui strategi penyelesaian proyek sesuai dengan timeline yang telah ditetapkan sebelumnya.

- Pembayaran kontraktor dan vendor yang lebih tepat waktu.

Langkah-langkah tersebut diambil untuk mempercepat pelaksanaan pembangunan yang lebih tepat waktu.

3. Peningkatan tata kelola perusahaan yang baik: Untuk meningkatkan tata kelola perusahaan yang baik PT. XYZ Tbk. dapat menjalankan beberapa proses antara lain: pelaksanaan audit Compliance, pelaksanaan Policy Fullfillment, pelaksanaan SOP Fullfillment.

4. Pelaksanaan product development: PT. XYZ Tbk. saat ini mampu meluncurkan berbagai produk yang inovatif sesuai dengan kebutuhan para pelanggannya. Hal ini dapat dilihat dari berbagai proyek yang diluncurkan oleh PT. XYZ Tbk. yang banyak direspon baik oleh para pelanggan.

\section{Perspektif Pembelajaran dan Pertumbuhan}

Berkaitan dengan perspektif pembelajaran dan pertumbuhan PT. XYZ Tbk. saat ini dapat melaksanakan beberapa kegiatan antara lain:

1. Peningkatan kinerja dan kompetensi para karyawan: PT. XYZ Tbk. melakukan peningkatan kinerja dan komptensi karyawan dengan cara pelaksanaan training melalui program-program pelatihan baik eksternal maupun internal perusahaan.

2. Peningkatan budaya organisasi: Dilakukan dengan cara pelaksanaan sosialisasi kepada karyawan mengenai budaya organisasi melalui penjelasan nilai-nilai perusahaan baik untuk karyawan baru ataupun karyawan lama secara rutin.

3. Peningkatan efisiensi dan efektifitas kerja para karyawan: Peningkatan tersebut dapat dilakukan melalui pelaksanaan sosialisasi untuk meningkatkan pemahaman mengenai kebijakan (policy) dan prosedur (procedure) yang berlaku saat ini.

\section{HASIL \& KESIMPULAN}

\section{Kesimpulan}

1. Dari hasil analisis SWOT (Strengths, Weaknesses, Opportunities, Threats) dapat disimpulkan bahwa PT. XYZ Tbk. memiliki 12 alternatif strategi yang dapat dipakai oleh perusahaan untuk mengatasi para pesaing dan mencapai tujuan sesuai dengan visi dan misi perusahaan.

2. Hasil analisis Balanced Scorecard pada PT. XYZ Tbk. menunjukkan bahwa:

a. Secara perspektif keuangan, perusahaan mengalami penurunan kinerja dalam hal keuangan, hal ini dapat dilihat dari rasio likuiditas - quick ratio perusahaan yang mengalami penurunan dari tahun 2015 dan 2016. Namun secara rasio likuiditas current ratio masih menunjukkan angka positif.

b. Secara perspektif pelanggan, perusahaan mengetahui benar bahwa indikator untuk melihat kinerja perusahaan dari sisi perspektif pelanggan ada 3, yaitu: tingkat kepuasan pelanggan, jumlah pelanggan baru dan persepsi pelanggan yang positif terhadap produk yang ditawarkan.

c. Secara perspektif proses bisnis internal perusahaan, perusahaan saat ini fokus pada pembenahan pada sisi proses bisnis internal perusahaan, antara lain: peningkatan efektifitas pemasaran, perencanaan dan pelaksanaan pembangunan yang 
tepat waktu, peningkatan tata kelola perusahaan yang baik dan pelaksanaan product development.

d. Secara perspektif pembelajaran dan pertumbuhan perusahaan, untuk mencapai visi dan misi perusahaan, diperlukan fondasi yang kuat pada sumber dayanya, fokus perusahaan ada pada: peningkatan kinerja dan kompetensi para karyawan, peningkatan budaya organisasi, peningkatan efisiensi dan efektifitas kerja para karyawan.

\section{Saran}

1. PT. XYZ Tbk. perlu melakukan komunikasi visi dan misi secara top down agar semua karyawan memiliki semangat dan keyakinan yang sama dalam mencapai tujuan perusahaan, sehingga perusahaan dapat terus tumbuh secara optimal.

2. PT. XYZ Tbk. perlu menerapkan pengukuran kinerja bisnis berdasarkan Balanced Scorecard yang dilihat dari 4 perspektif. Agar penerapan ini dapat berjalan dengan baik diperlukan keterlibatan dan komitmen dari Manajemen Puncak perusahaan serta perlu melakukan monitoring dan evaluasi secara berkala.

3. PT. XYZ Tbk. perlu mewaspadai perubahan permintaan akan property sesuai dengan kebutuhan dan keinginan para konsumennya, perkembangan teknologi untuk menunjang saluran pemasaran yang baru, supply maupun demand dari produk property dan mengatisipasi setiap perubahan kebijakan pemerintah.

\section{DAFTAR PUSTAKA}

Christina, Ni Puttu Yessy dan I PUtu Sudana (2006). Penilaian Kinerja Pada PT. Adhi Karya Dengan Pendekatan Balanced Scorecard. E-Jurnal Akuntansi Universitas Udayana 5.3, 516-529, 2302-8556.

Hasanah, Ilmiatul, Jeni Susyanti, Budi Wahono. (2017). Analisa Kinerja Keuangan Perusahaan Real Estate dan Property Yang Terdaftar di Bursa Efek Indonesia Sebelum dan Selama Pemerintahan Presiden Jokowi: Warta Ekonomi Vol.07, NO. 17 Februari 2017, 47.

Kaplan, Robert S. and David P. Norton (1996). Balanced Scorecard : Translating Strategy into Action. Boston : Harvard Business School Press.

Kaplan, Robert S. and David P. Norton (2007). Using the Balanced Scorecard as A Strategic Management System into Action. Boston: Harvard Business Review.

Rangkuti, Freddy (2011). Swot Balanced Scorecard, Teknik Menyusun Strategi Korporat yang Efektif plus Cara Mengelola Kinerja dan Resiko. Cetakan ke-2. Jakarta : PT. Gramedia Pustaka Utama.

Makhijani, Naresh dan James Creelman (2002). Menciptakan Balance Scorecard Untuk Organisasi Jasa Keuangan. Jakarta : Erlangga Group.

Vargas-Sanchez, Alfonso and Juan Diego Borrero-Sanchez (2006). The Case of GIVSA: Application of the Balanced Scorecard to A Local Publicly Owned Company. International Journal of Case Method Research \& Application, XVIII (3),1554-7752.

Rahardja, Untung, Muhammad Yusup, Eva Rosyifah (2012). Optimalisasi Key Performance Indicator (KPI) Melalui Pendekatan Balanced Scorecard Upaya Mengimplementasikan Performance Management System (PMS) pada Perguruan Tinggi.

L. Singgih, Moses, Kristiana Asih Damayanti, Renny Ocatavia. (2001). Pengukuran dan Analisa Kinerja dengan Metode Balance Scorecard di PT. "X": Jurnal Teknik Industri Vol.3, NO. 2, 48-56.

Wibisono, Dermawan (2012). How To Create A World Class Company : Panduan Bagi Manajer dan Direktur. Jakarta : PT. Gramedia Pustaka Utama. 


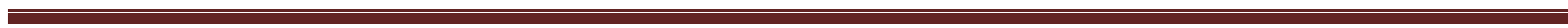
$\cdot$ 